\title{
Decreased Serum Brain-Derived Neurotrophic Factor Levels in Elderly Korean with Dementia
}

\section{Jung Goo Lee ${ }^{1}$ \\ Bae Sub Shin ${ }^{2}$ \\ Young Sun You ${ }^{3}$ \\ Ji Eun Kim ${ }^{4}$ \\ Sung Wook Yoon ${ }^{5}$ \\ Dong Wook Jeon ${ }^{5}$ \\ Jun Hyung Baek ${ }^{5}$ \\ Sung Woo Park ${ }^{6}$ \\ Young Hoon $\mathrm{Kim}^{6}$}

'Department of Psychiatry, Dong Suh Mental Hospital and Paik Institute for Clinical Research, Inje University, Busan,

${ }^{2}$ Department of Psychiatry, Guduk Hospital, Busan,

${ }^{3}$ Department of Psychiatry, Dong Nam Hospital, Gimhae, ${ }^{4}$ Department of Psychiatry, Dong Suh Mental Hospital, Masan, ${ }^{5}$ Department of Psychiatry, Busan Paik Hospital, Inje Medical College, Busan, 'Department of Psychiatry, School of Medicine and Paik Institute for Clinical Research, Inje University, Busan, Korea

\section{Correspondence}

Young Hoon Kim, MD, PhD

Department of Psychiatry,

School of Medicine and

Paik Institute for Clinical Research,

Inje University, 633-165 Gaegeum-dong,

Busanjin-gu, Busan 614-735, Korea

Tel $+82-51-890-6189$

Fax +82-51-894-2532

E-mail npkyh@chol.com

cc) This is an Open Access article distribute under the terms of the Creative Commons Attribution Non-Commercial License (http://creativecommons.org/licenses/by-nc/3.0) which permits unrestricted non-commercial use, distribution, and reproduction in any medium, provided the original work is properly cited.
Objective The primary purpose of this study was to investigate the differences in the serum brain-derived neurotrophic factor (BDNF) level between elderly Korean people over 65 years with and without dementia.

Methods 171 individuals over 65 years were enrolled in this study. Screening for cognitive impairments was carried out using the Mini-Mental Status Examination-Korean version (MMSE-KC). One hundred thirty-two subjects scored below 1.5 standard deviations (SD) of the mean MMSE-KC score, and these were evaluated using the Consortium to Establish a Registry for Alzheimer's Disease, Korean version (CERAD-K) and the Geriatric Depression Scale (GDS). The Clinical Dementia Rating Scale (CDRS) and the Diagnostic and Statistical Manual of Mental Disorders, fourth edition (DSM-IV) diagnostic criteria were used for further evaluation. Subjects with a CDRS score of 1 or higher were classified as having Alzheimer's disease (AD), and subjects with a CDRS score of 0.5 were classified as having a mild cognitive impairment (MCI). Subjects with a CDRS score of 0 were classified as having aging-associated cognitive decline (AACD). Serum BDNF levels were analyzed using the enzyme-linked immunosorbent assay (ELISA) method.

Results The serum BDNF levels were significantly lower in the subjects with MCI and AD compared with the healthy controls $(\mathrm{p}<0.01)$. A significant correlation was found between the total MMSE-KC score and serum BDNF level $(\mathrm{r}=0.295 ; \mathrm{p}<0.01)$. However, no significant correlation was observed between the severity of MMSE-KC and the total GDS score. A significant difference was found in the total score of GDS between the AACD group and subjects with $\mathrm{AD}(\mathrm{p}<0.05)$.

Conclusion This study suggested that BDNF might be involved in the pathophysiology of cognitive decline in elderly people.

Psychiatry Invest 2009;6:299-305

Key Words Alzheimer's disease, Mild cognitive impairment, Brain-derived neurotrophic factor, Depression.

Received: August 10, 2009 Revised: October 15, 2009 Accepted: October 29, 2009 Available online: November 11, 2009

\section{Introduction}

Dementia refers to a disease that causes the deterioration of general memory, speech, executive function, visuospatial function, and other cognitive functions. Patients with dementia also manifest behavioral disturbances, personality change, and emotional disturbances, and these symptoms often cause social, professional, or occupational impairment. ${ }^{1}$ Due to the rapid increase in the elderly population, the number of patients with dementia is also rising sharply, and the consequent problems affect not only the patients themselves but also their families, creating wider social problems. ${ }^{2}$ It has been reported that Alzheimer's disease (AD) accounts for approximately 50\% of all dementia. ${ }^{3}$ The characteristics of $\mathrm{AD}$ are the formation of neuritic plaques due to the deposition of beta-amyloid protein and the formation of neurofibrillary tangles in the brain. Blasko and Grubeck-Loebenstein ${ }^{4}$ reported that 10-20 years prior to the de- 
velopment of $\mathrm{AD}$, impairment of brain metabolism was already developing. It is thought that risk factors of $\mathrm{AD}$ include age, sex, education level, family history, head trauma, a history of depression, and smoking. ${ }^{5}$

However, according to recent studies, neurotrophins such as brainderived neurotrophic factor (BDNF) might also be associated with the pathogenesis of $\mathrm{AD} .{ }^{6-9} \mathrm{Ha}-$ shimoto et al. ${ }^{11}$ reported that the BDNF signaling pathway and MetBDNF may affect memory and hippocampal function in humans.

BDNF polymorphism could be a risk factor for rapid disease progression in preclinical $\mathrm{AD}{ }^{10,11}$ In postmortem brain analyses of patients with $\mathrm{AD}$, the level of BDNF messenger RNA (mRNA) in the hippocampus and the cortex was decreased. ${ }^{12,13}$ The reduction of the BDNF level in the hippocampus and the cortex is thought to induce neurodegenerative changes in the brain. ${ }^{14}$ Yasutake et al. ${ }^{15}$ reported that serum BDNF concentrations were significantly lower in subjects with severe AD than in either healthy controls or subjects with vascular dementia. Gunstad et al. ${ }^{16}$ reported that higher serum BDNF levels were associated with better neuropsychological function in healthy older adults.

Yu et al. ${ }^{17}$ reported that reduced BDNF levels may play a role in the pathophysiology of amnestic mild cognitive impairemnt. In clinical studies, increased BDNF serum concentrations have been observed following treatment with lithium and donepezil. ${ }^{18,19}$

BDNF is a nerve growth factor that is expressed widely in the adult mammalian brain, and it has been shown to play an important role in the development and survival of neurons. BDNF is a subject of interest in the study on the pathogenesis of neurodevelopmental or neurodegenerative disorders. ${ }^{20,21}$

The incidence of depression in individuals with $\mathrm{AD}$ has been reported to be $23-51 \%{ }^{22}$ A correlation is known to exist between cognitive function and depression. ${ }^{22-24}$ Depression, therefore, might be associated with a deterioration of cognitive function. ${ }^{25-27}$ So depression may have a negative effect on cognitive function and on the ability to perform the functions required for daily life in patients with $\mathrm{AD}{ }^{2}$ Laske et al. ${ }^{28}$ observed inverse correlations between serum BDNF concentrations and depressive symptoms. In this study, therefore, we investigated whether serum BDNF concentrations differed between a normal group, an aging associated cognitive decline (AACD) group, an mild cognitive impairment (MCI) group, and an $\mathrm{AD}$ group.

We also evaluated the correlation between depression and serum BDNF concentration and the differences in serum BDNF concentration according to the severity of depression.

\section{Methods}

\section{Subjects}

Six hundred twenty-eight subjects aged 65 years or older participated in this study. The subjects were patients who were able to participate in the project voluntarily during the research period, and a written consent was obtained. The study protocol was approved by the Institutional Review Board (IRB) of Busan Paik Hospital, Busan. A dementia screening test was performed using the Korean version of the Mini-Mental State Examination (MMSE-KC), and for the final diagnosis of $\mathrm{AD}$, the diagnostic standard of the Diagnostic and Statistical Manual of Mental Disorders, fourth edition (DSM-IV) and that of the National Institute of Neurologic and Communicative Disorders and Stroke and Alzheimer's Disease and Related Disorder Association (NINDS-ADRDA) were used. ${ }^{29,30} \mathrm{~A}$ total of 371 subjects agreed to blood sampling to evaluate serum BDNF levels. A 5-cc sample of venous blood was collected from subjects between 11:00 and $24: 00 \mathrm{~h}$ each day. Subjects with or psychotic features or history of depressive episodes according to DSMIV criteria were excluded from the study. In addition, subjects who had clinically significant physical abnormalities based on both physical and laboratory examination or who had a history of organic brain abnormality or psychotropic drug misuse were excluded from the study.

\section{Methods}

A screening test for dementia was performed on all subjects using the MMSE-KC. One hundred subjects whose MMSE-KC scores were within 1.5 standard deviation (SD) of the mean were classified as "normal", and no further tests for dementia were performed on these subjects. Thirty-nine subjects with MMSE-KC scores above 25 were selected as the normal control group. One hundred thirtytwo subjects had MMSE-KC scores more than 1.5 SD above the mean and underwent further, more comprehensive examinations. These comprehensive tests were performed using two testing steps. The first was the Korean version of the Consortium to Establish a Registry for Alzheimer's Disease (CERAD-K) neurocognitive battery, and the second was the full version of CERAD-K, which was administered by psychiatrists. ${ }^{31}$ Subjects were classified according to their score on the Clinical Dementia Rating Scale (CDRS), which was a part of the second test. Forty-four subjects were classified as the 0-point group, 41 subjects were classified as the 0.5 -point group, and 47 subjects formed the group higher than 1 point.

Finally, members of the group with CDRS higher than 1 point were evaluated by psychiatrists using the diagnostic standards of DSM-IV and NINDS-ADRDA, and 
all members of the group were diagnosed with AD. Previous studies have reported that some individuals with a CDRS score of higher than 0.5 may be in the initial stages of $\mathrm{AD}$; however, in our study, they were all classified as having $\mathrm{MCI}^{32}$

The diagnosis of MCI was performed using the diagnostic criteria proposed by Petersen et al. ${ }^{33}$ These diagnostic criteria were as follows. 1) Subjects should have memory-impairment problems identified by informants, 2) in comparison with their peers, subjects should have memory impairment, 3 ) relatively speaking, general cognition should be conserved, 4) the ability to perform daily living activities should be conserved, and 5) they should not be diagnosed as having dementia. Among the subjects, those with MMSE-KC scores less than 1.5 SD from the mean were classified as "normal", and therefore, comprehensive tests were not performed on them. However, these subjects may have had MCI. The subjects with CDRS scores of 0 were not diagnosable as having MCI. However, the MMSE-KC scores adjusted for age and schooling were higher in these subjects than in others, by $1.5 \mathrm{SD}$; thus, they were considered to belong in the AACD group.

The CDRS uses six detailed categories to evaluate cognitive function and all areas of social function in subjects with dementia. The categories are memory, orientation, determination and ability to solve problems, social activity, home life and hobbies, and hygiene and grooming. ${ }^{32}$ CDRS scores can be represented according to two different methods using scores in the above six categories. The first method is to calculate the "Sum of Boxes (CDR-SB)" by adding the scores of all six categories. The second method is to determine the global CDRS score based on memory. According to this method, a CDR score of 0 indicates no dementia (none), and a CDR score of 0.5 indicates questionable dementia. A CDR score of 1 represents mild dementia, 2 indicates moderate dementia, 3 indicates severe dementia, 4 suggests profound dementia, and a CDR score of 5 implies terminal dementia. While evaluating CDRS, raters must be careful to evaluate only that functional deterioration caused by cognitive impairment. Functional deterioration caused by physical conditions such as stroke or social and emotional problems should not be considered. ${ }^{34}$

For the evaluation of depression, the Geriatric Depression Scale (GDS) was used. This scale consists of 30 questions and has previously been applied very usefully as a screening test for geriatric depression. ${ }^{35}$ In this study, the Korean version of the Geriatric Depression Scale (GDS-K) was used. ${ }^{36}$ The GDS-K was adopted during the second step of testing, and subjects with total GDS-K scores higher than 20 were considered to have depression. ${ }^{36}$

\section{Measurement of serum brain-derived neurotrophic factor concentration}

Venous blood samples $(5 \mathrm{~mL})$ from the upper arm of each subject were collected in anticoagulant-free tubes between $08: 00 \mathrm{~h}$ and 12:00 h. The samples were incubated at room temperature for $1 \mathrm{~h}$ followed by $1 \mathrm{~h}$ at $4^{\circ} \mathrm{C}$ before the serum was isolated. Samples were then centrifuged at $2,000 \times \mathrm{g}$ at $4^{\circ} \mathrm{C}$ for $10 \mathrm{~min}$. The supernatants were transferred to an Eppendorff tube, and the amount of BDNF was measured using enzyme-linked immunosorbent assay (ELISA) kits (Promega, Madison, WI, USA). Monoclonal anti-mouse-BDNF antibody was added to 96-well plates and they were incubated at $4{ }^{\circ} \mathrm{C}$ for $12 \mathrm{~h}$. The next day, the plates were washed with a wash buffer $(20 \mathrm{mM}$ Tris- $\mathrm{HCl} \mathrm{pH} 7.6,150 \mathrm{mM} \mathrm{NaCl}$, $0.05 \%$ Tween 20 ), blocked for nonspecific binding, and incubated at room temperature for $1 \mathrm{~h}$ After washing, BDNF standards and samples were added to the wells, and plates were incubated for $2 \mathrm{~h}$ at room temperature. The anti-human BDNF antibody was then added and incubated for $2 \mathrm{~h}$ at room temperature. After washing, the anti-IgY antibody conjugated to horseradish peroxidase was added and incubated for $1 \mathrm{~h}$ at room temperature. Any unbound conjugate was removed by washing. The solution was incubated with a chromogenic substrate, and the reaction was stopped using $1 \mathrm{~N}$ hydrochloric acid. BDNF concentration was measured at $450 \mathrm{~nm}$ using a microplate reader (SLT Spectra; SLT Instruments, Salzburg, Austria).

\section{Statistical analysis}

Chi-square tests and/or analysis of variance's (ANOVA's) were conducted to assess the demographic data. An ANOVA was used to analyze differences in serum BDNF concentration between the normal, AACD, MCI, and $\mathrm{AD}$ groups. We also used an ANOVA to assess differences in serum BDNF concentration according to the severity of the depression. Pearson's correlation test was used $(p<0.05)$ to assess correlations among MMSE-KC scores, severity of depression, and serum BDNF concentration. The Scheffe method was used for post-hoc analysis.

\section{Results}

\section{Demographic data}

Educational level was significantly lower in the AD group than in any of the other groups $(\mathrm{p}<0.01)$. The mean MMSE-KC score of the AD group was significantly lower than that for any other group $(\mathrm{p}<0.01)($ Table 1$)$.

\section{Cognitive impairment and serum brain-derived neurotrophic factor concentration}

The average concentration of serum BDNF in the nor- 
TABLE 1. Demographic and clinical data of subjects

\begin{tabular}{|c|c|c|c|c|c|}
\hline & \multicolumn{3}{|c|}{ MMSE-KC 1.5 SD below } & \multicolumn{2}{|c|}{ MMSE-KC 0-1.5 SD } \\
\hline & CDRS $1 \geq$ & CDRS 0.5 & CDRS 0 & Raw score $25<$ & Raw score $25 \geq$ \\
\hline No. of subject & 47 & 41 & 44 & 61 & 39 \\
\hline $\operatorname{Sex}(M / F)$ & $14 / 33$ & $17 / 24$ & $20 / 24$ & $8 / 53$ & $16 / 23$ \\
\hline Age & $75.1(6.4)$ & $74.1(5.7)$ & $73.0(4.2)$ & $75.4(4.8)$ & $72.8(5.0)$ \\
\hline Education (years)** & $3.1(4.0)$ & $5.8(2.7)$ & $6.5(4.3)$ & $6.6(2.4)$ & $6.7(3.1)$ \\
\hline MMSE-KC** & $13.7(5.0)$ & 17.9 (3.3) & $19.1(2.6)$ & $19.8(2.9)$ & 27.4 (1.5) \\
\hline
\end{tabular}

Mean (SD). ${ }^{* *} \mathrm{p}<0.01$ CDRS 0, 0.5 vs CDRS 1. MMSE-KC: Mini Mental State Examination of Korean version, CDRS: Clinical Dementia Rating Scale, SD: standard deviation

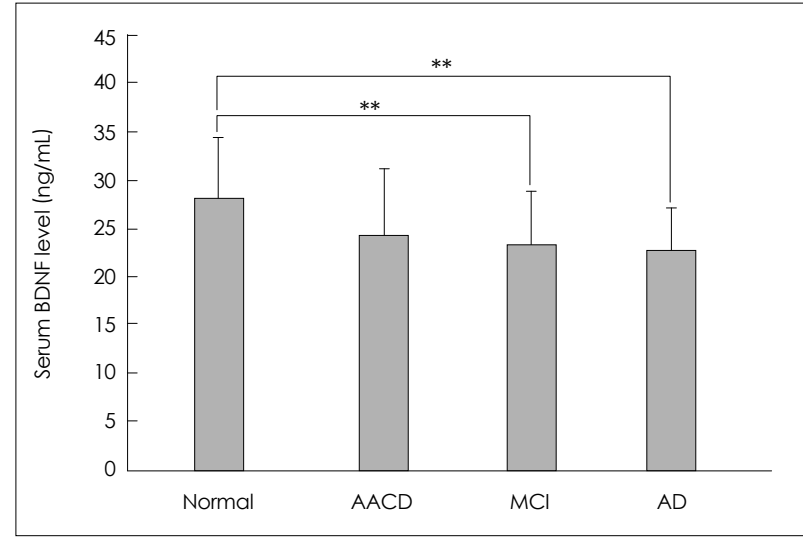

FIGURE 1. Serum BDNF levels of subjects. ${ }^{* *} p<0.01$. BDNF: brain-derived neurotrophic factor, AACD: age-associated cognitive decline, $\mathrm{MCl}$ : mild cognitive impairment, $\mathrm{AD}$ : Alzheimer's disease.

mal group was $27.9 \pm 6.9 \mathrm{ng} / \mathrm{mL}$. In the AACD group, average concentration of serum BDNF was $24.2 \pm 7.4$ $\mathrm{ng} / \mathrm{mL}$; in the MCI group, it was $22.8 \pm 6.3 \mathrm{ng} / \mathrm{mL}$; and in the $\mathrm{AD}$ group, it was $22.9 \pm 5.0 \mathrm{ng} / \mathrm{mL}$. In the MCI and $\mathrm{AD}$ groups, average serum BDNF concentration was significantly lower than that in the normal group $(\mathrm{p}<$ 0.01)(Figure 1).

\section{Cognitive impairment and depression}

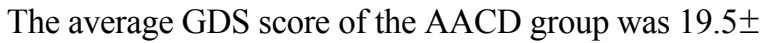
7.2 , the average score of the MCI group was $22.4 \pm 6.0$, and the average score of the AD group was 23.3 \pm 4.9 . The average GDS score of the AD group was significantly higher than that for the AACD group $(\mathrm{p}<0.05)$ (Figure 2). The GDS score of the normal elderly group with MMSE-KC scores higher than 1.5 SD from the mean was not evaluated.

\section{Depression and serum brain-derived neurotrophic factor concentration}

In the 34 subjects with depression, the average concentration of serum BDNF was $23.3 \pm 6.1 \mathrm{ng} / \mathrm{mL}$, whereas the average BDNF concentration among the 98 cases in the group without depression was $22.4 \pm 6.8 \mathrm{ng} / \mathrm{mL}$; no significant statistical difference between the two groups

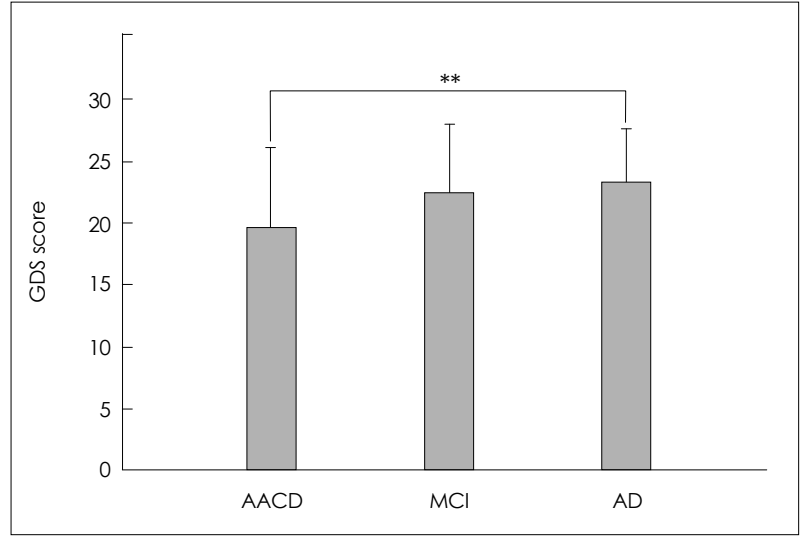

FIGURE 2. Mean GDS scores of subjects with MMSE-KC score 1.5 SD below. ${ }^{* *} p<0.01$. GDS: geriatric depression scale, MMSEKC: Mini Mental State Examination of Korean version, SD: standard deviation, AACD: age-associated cognitive decline, MCl: mild cognitive impairment, $A D$ : Alzheimer's disease.

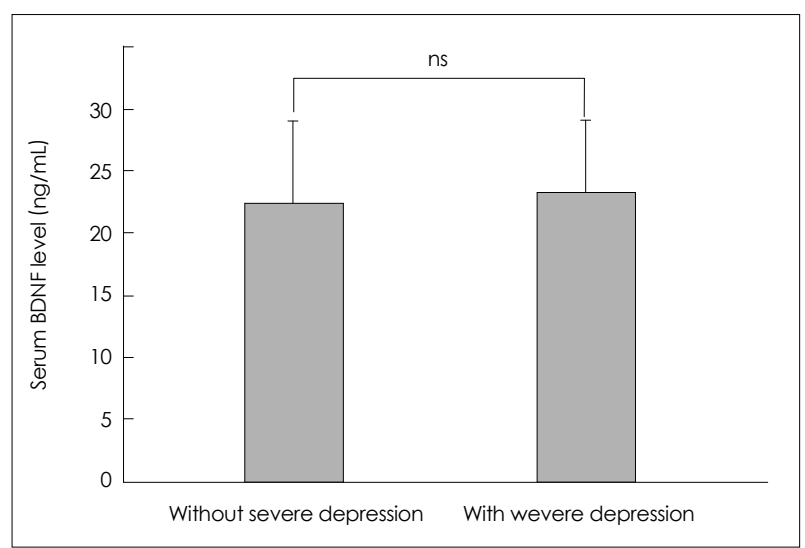

FIGURE 3. Serum BDNF levels in the two groups with (GDS $\geq 20$ ) or without severe depression (GDS<20). BDNF: brain-derived neurotrophic factor, GDS: geriatric depression scale.

was found (Figure 3).

\section{Korean version of the Mini-Mental State Examination score and serum brain-derived neurotrophic factor concentration}

A correlation was observed between MMSE-KC score and serum BDNF concentration $(r=0.295 ; \mathrm{p}<0.01)$ (Figure 4). 


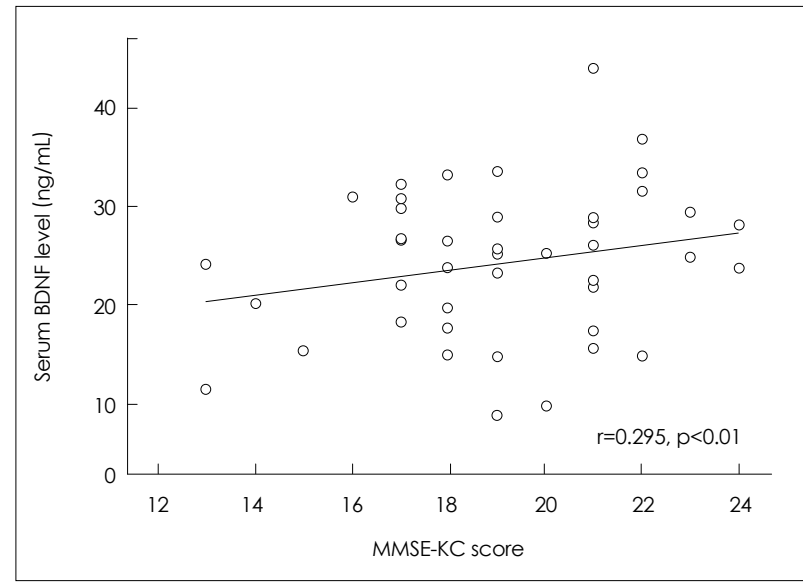

FIGURE 4. Correlation between serum BDNF levels and total scores of MMSE-KC in all subjects. BDNF: brain-derived neurotrophic factor, MMSE-KC: Mini Mental State Examination of Korean version

\section{Korean version of the Mini-Mental State Examination score and depression}

In subjects with MMSE-KC scores of 1.5 SD below the mean, an analysis of the relationship between MMSE$\mathrm{KC}$ scores and GDS scores showed no significant correlation.

\section{Discussion}

It has been reported previously that BDNF can cross the blood-brain barrier (BBB), and in animal studies, a positive correlation between the concentration of BDNF in the serum and in the cerebral cortex has been shown. ${ }^{37-39}$ Therefore, it could be inferred that a change in BDNF in the central nervous system may be associated with a corresponding change in serum BDNF. ${ }^{12}$

In this study, the correlation between cognitive impairment and changes in serum BDNF concentration was evaluated. We also investigated the possibility of a correlation between cognitive impairment and depression. We found that the more severe the cognitive impairment was, the greater the reduction of serum BDNF concentration tended to be. This finding is similar to previous reports. ${ }^{12}$ According to recent studies, neurotrophic factors such as BDNF are associated with the pathophysiology of $\mathrm{AD} .{ }^{40}$ In postmortem analyses of the brains of patients with $\mathrm{AD}, \mathrm{BDNF}$ concentrations in the temporal cortex and the hippocampus have been found to be decreased, as have BDNF concentrations in the frontal cortex. $^{41,42}$ In addition, it has been reported that the deposition of beta-amyloid protein is involved in the synthesis of BDNF and signal transduction, resulting in a blockage of, synaptic function and accelerated neuronal degeneration. ${ }^{40}$ Such results support the hypothesis that a reduction of BDNF concentration is involved in the etiology of AD.

Numerous studies have reported that after an ischemic brain injury, BDNF concentrations in the cranial cortex and the number of neurons in the hippocampus were increased. ${ }^{43-45}$ Such results strongly suggest that BDNF plays a neuroprotective role in ischemic brain injury. In a postmortem analysis of an AD brain, BDNF concentration was also found to be increased. This study also hypothesized that the BDNF concentration was increased by a compensation mechanism. ${ }^{46}$ Laske et al. ${ }^{14}$ showed that in patients with mild Alzheimer-type dementia, serum BDNF concentration was higher than in a healthy control group. ${ }^{12}$ They assumed that BDNF concentration was elevated temporarily as a compensatory mechanism at the initiation of degenerative changes, and thus, serum BDNF concentration was higher in the mild AD group than in the normal group. In our study, most patients with $\mathrm{AD}$ were mild cases, and compared with the normal group, their serum BDNF concentration was lower. The result of our study contradicts the above result and thus does not support the compensation mechanism theory described above. However, our study did detect a positive correlation between MMSE-KC score and serum BDNF concentration, which supports previous findings. ${ }^{12}$ Therefore, the result of our study supports the hypothesis that a reduction of BDNF concentration is associated with a deterioration of cognitive function. ${ }^{40}$

We found that the average GDS score in the AD group was significantly higher than that in the AACD group. It is widely accepted that depression can be severe in individuals with $\mathrm{AD} .^{22,47}$ It has also been reported that depression may be a risk factor for the development of AD. ${ }^{48}$ However, in the present study, no significant difference in average GDS score was found between the $\mathrm{MCI}$ and AD groups.

Generally, it could be predicted that depression would be more severe among individuals in the MCI group than among those in the AACD group, and it has been reported that in subjects with MCI and accompanying depressive symptoms, the prevalence of $\mathrm{AD}$ is increased. ${ }^{49}$ Depressive symptoms have a negative effect on cognitive function and are therefore sometimes referred to as pseudodementia. ${ }^{50-52}$ On the other hand, it has been also reported that neuronal degeneration progresses more rapidly in the brains of subjects with AD. ${ }^{53}$

In the present study, no correlation was found between MMSE-KC and GDS scores. This finding contradicts previous studies showing that depressive symptoms are associated with a deterioration of cognitive function. ${ }^{22-24,54}$ A reason for this discrepancy could be that in this study, GDS was not evaluated for subjects with MMSE-KC scores of more than 1.5 SD from the mean, so correla- 
tions between the two groups could not be examined. In addition, the tests used in this study to assess cognitive function and depressive symptoms are used widely for screening tests, and thus in future research, correlations should be examined by applying more accurate and objective evaluation tools. Because of these limitations, any correlation between deterioration of cognitive function and depression could not be elucidated in our study.

A comparison of serum BDNF concentration according to severity of depressive symptoms revealed no significant differences in this study. This contradicts the finding of a previous study, that in a group with depression, serum BDNF concentration was lower than in the healthy control group. ${ }^{55}$ We found no correlation between depressive symptoms and serum BDNF concentration; nonetheless, the deterioration of cognitive function correlated with serum BDNF concentration. Thus, regardless of the presence or absence of depression in subjects with AD, BDNF concentration was decreased. This supports the hypothesis that a reduction of BDNF influences the deterioration of cognitive function. In this study, it has been suggested that a reduction of serum BDNF concentration may be viewed as a biomarker of the deterioration of cognitive function. ${ }^{12}$

The limitations of this study are as follows. In the group with MMSE-KC scores lower than 1.5 SD below the mean, CDRS was not evaluated, and thus, some MCI patients were excluded from the study. Because GDS was not measured in this group, the correlation between depression and cognitive impairment could not be assessed accurately. In addition, classification of cognitive impairment is generally applied to cases lower than 1.0 SD from the mean, but in the present study, the AACD group was classified as those with a score lower than 1.5 SD from the mean. ${ }^{55}$ In addition, as mentioned above, some initial-stage AD patients are thought to have been included in the group with a CDRS score lower than 0.5; yet, in our study, all these subjects were classified as the MCI group.

The results of our study support the hypothesis that BDNF concentration is involved in the pathophysiology of AD. Serum BDNF concentration among individuals varies greatly; nevertheless, a reduction of BDNF concentration in an individual may be applied as a biomarker of AD. In our study, a trend toward severe depression was detected in subjects with $\mathrm{AD}$ but not in MCI patients.

However, the correlation between the severity of depressive symptoms and BDNF concentration could not be elucidated. Further research is required to reexamine this issue using supplementary research methods and more accurate evaluation tools.

\section{REFERENCES}

1. Dugu M, Neugroschl J, Sewell M, Marin D. Review of dementia. Mt Sinai J Med 2003;70:45-53.

2. Cotter VT. The burden of dementia. Am J Manag Care 2007;13 Suppl 8:S193-S197.

3. Román GC, Tatemichi TK, Erkinjuntti T, Cummings JL, Masdeu JC, Garcia JH, et al. Vascular dementia: diagnostic criteria for research studies. Report of the NINDS-AIREN International Workshop. Neurology 1993;43:250-260.

4. Blasko I, Grubeck-Loebenstein B. Role of the immune system in the pathogenesis, prevention and treatment of Alzheimer's disease. Drugs Aging 2003;20:101-113.

5. Gorelick PB. Risk factors for vascular dementia and Alzheimer disease. Stroke 2004;35(11 Suppl 1):2620-2622.

6. Kunugi H, Ueki A, Otsuka M, Isse K, Hirasawa H, Kato N, et al. A novel polymorphism of the brain-derived neurotrophic factor (BDNF) gene associated with late-onset Alzheimer's disease. Mol Psychiatry 2001;6:83-86.

7. Fahnestock M, Garzon D, Holsinger RM, Michalski B. Neurotrophic factors and Alzheimer's disease: are we focusing on the wrong molecule? J Neural Transm suppl 2002:241-252.

8. Riemenschneider M, Schwarz S, Wagenpfeil S, Diehl J, Müller U, Förstl $\mathrm{H}$, et al. A polymorphism of the brain-derived neurotrophic factor (BDNF) is associated with Alzheimer's disease in patients lacking the apolipoprotein E epsilon4 allele. Mol Psychiatry 2002;7:782-785.

9. Ventriglia M, Bocchio Chiavetto L, Benussi L, Binetti G, Zanetti O, Riva MA, et al. Association between the BDNF 196 A/G polymorphism and sporadic Alzheimer's disease. Mol Psychiatry 2002;7:136-137.

10. Hashimoto R, Hirata Y, Asada T, Yamashita F, Nemoto K, Mori T, et al. Effect of the brain-derived neurotrophic factor and the apolipoprotein E polymorphisms on disease progression in preclinical Alzheimer's disease. Genes Brain Behav 2009;8:43-52.

11. Hashimoto R, Moriguchi Y, Yamashita F, Mori T, Nemoto K, Okada T, et al. Dose-dependent effect of the Val66Met polymorphism of the brain-derived neurotrophic factor gene on memory-related hippocampal activity. Neurosci Res 2008;61:360-367.

12. Hock C, Heese K, Hulette C, Rosenberg C, Otten U. Region-specific neurotrophin imbalances in alzheimer disease: decreased levels of brain-derived neurotrophic factor and increased levels of nerve growth factor in hippocampus and cortical areas. Arch Neurol 2000;57:846851.

13. Holsinger RM, Schnarr J, Henry P, Castelo VT, Fahnestock M. Quantitation of BDNF mRNA in human parietal cortex by competitive reverse transcription-polymerase chain reaction: decreased levels in Alzheimer's disease. Brain Res Mol Brain Res 2000;76:347-354.

14. Laske C, Stransky E, Leyhe T, Eschweiler GW, Wittorf A, Richartz E, et al. Stage-dependent BDNF serum concentrations in Alzheimer's disease. J Neural Transm 2006;113:1217-1224.

15. Yasutake C, Kuroda K, Yanagawa T, Okamura T, Yoneda H. Serum BDNF, TNF-alpha and IL-1beta levels in dementia patients: comparison between Alzheimer's disease and vascular dementia. Eur Arch Psychiatry Clin Neurosci 2006;256:402-406.

16. Gunstad J, Benitez A, Smith J, Glickman E, Spitznagel MB, Alexander T, et al. Serum brain-derived neurotrophic factor is associated with cognitive function in healthy older adults. J Geriatr Psychiatry Neurol 2008;21:166-170.

17. Yu H, Zhang Z, Shi Y, Bai F, Xie C, Qian Y, et al. Association study of the decreased serum BDNF concentrations in amnestic mild cognitive impairment and the Val66Met polymorphism in Chinese Han. J Clin Psychiatry 2008;69:1104-1111.

18. Leyhe T, Stransky E, Eschweiler GW, Buchkremer G, Laske C. Increase of BDNF serum concentration during donepezil treatment of patients with early Alzheimer's disease. Eur Arch Psychiatry Clin Neurosci 2008;258:124-128. 
19. Leyhe T, Eschweiler GW, Stransky E, Gasser T, Annas P, Basun H, et al. Increase of BDNF serum concentration in lithium treated patients with early Alzheimer's disease. J Alzheimers Dis 2009;16:649-656.

20. Thoenen H. Neurotrophins and neuronal plasticity. Science 1995;270: 593-598.

21. Lewin GR, Barde YA. Physiology of the neurotrophins. Annu Rev Neurosci 1996;19:289-317.

22. Migliorelli R, Teson A, Sabe L, Petracchi M, Leiguarda R, Starkstein SE. Prevalence and correlates of dysthymia and major depression among patients with Alzheimer's disease. Am J Psychiatry 1995;152: $37-44$.

23. Reichman WE, Coyne AC. Depressive symptoms in Alzheimer's disease and multi-infarct dementia. J Geriatr Psychiatry Neurol 1995;8: 96-99.

24. Tueth MJ. How to manage depression and psychosis in Alzheimer's disease. Geriatrics 1995;50:43-46.

25. Reifler BV, Larson E, Hanley R. Coexistence of cognitive impairment and depression in geriatric outpatients. Am J Psychiatry 1982;139:623626.

26. Breen AR, Larson EB, Reifler BV, Vitaliano PP, Lawrence GL. Cognitive performance and functional competence in coexisting dementia and depression. J Am Geriatr Soc 1984;32:132-137.

27. Pearson JL, Teri L, Reifler BV, Raskind MA. Functional status and cognitive impairment in Alzheimer's patients with and without depression. J Am Geriatr Soc 1989;37:1117-1121.

28. Laske C, Stransky E, Eschweiler G, Wittorf A, Richartz-Salzburger E, Bartels M, et al. BDNF serum concentrations in patients with Alzheimer's disease are associated with depressive mood states. Neurol Psychiatr Brain Res 2005;12:1-4

29. Mckhann G, Drachman D, Folstein M, Katzman R, Price D, Stadlan EM. Clinical diagnosis of Alzheimer's disease: report of the NINCDSADRDA Work Group under the auspices of Department of Health and Human Services Task Force on Alzheimer's Disease. Neurology 1984; 34:939-944.

30. American Psychiatric Association. Diagnostic and Statistical Manua of Mental Disorders. 4th ed. Text revision. Washington DC: American Psychiatric Association; 2000.

31. Lee JH, Lee KU, Lee DY, Kim KW, Jhoo JH, Kim JH, et al. Development of the Korean version of the Consortium to Establish a Registry for Alzheimer's Disease Assessment Packet (CERAD-K): clinical and neuropsychological assessment batteries. J Gerontol B Psychol Sci Soc Sci 2002;57:47-53

32. Morris JC. The Clinical Dementia Rating (CDR): current version and scoring rules. Neurology 1993;43:2412-2414.

33. Petersen RC, Smith GE, Waring SC, Ivnik RJ, Tangalos EG, Kokmen E. Mild cognitive impairment: clinical characterization and outcome. Arch Neurol 1999;56:303-308.

34. Choi SH, Na DL, Lee BH, Hahn DS, Jeong JH, Yoon SJ, et al. Estimating the validity of Korean version of expanded Clinical Dementia Rating (CDR) scale. J Korean Neurol Assoc 2001;19:585-591.

35. Yesavage JA, Brink TL, Rose TL, Lum O, Huang V, Adey M, et al Development and validation of a geriatric depression screening scale: a preliminary report. J Psychiatr Res 1982-1983;17:37-49.

36. Cho MJ, Bae JN, Suh GH, Hahm BJ, Kim JK, Lee DW, et al. Validation of geriatric depression scale, Korean version (GDS) in the assessment of DSM-III-R major depression. J Korean Neuropsychiatr Assoc 1999;38:48-63.

37. Poduslo JF, Curran GL. Permeability at the blood-brain and bloodnerve barriers of the neurotrophic factors: NGF, CNTF, NT-3, BDNF.
Brain Res Mol Brain Res 1996;36:280-286.

38. Pan W, Banks WA, Fasold MB, Bluth J, Kastin AJ. Transport of brainderived neurotrophic factor across the blood-brain barrier. Neuropharmacology 1998;37:1553-1561.

39. Karege F, Schwald M, Cisse M. Postnatal developmental profile of brain-derived neurotrophic factor in rat brain and platelets. Neurosci Lett 2002;328:261-264.

40. Mattson MP, Maudsley S, Martin B. BDNF and 5-HT: a dynamic duo in age-related neuronal plasticity and neurodegenerative disorders. $\mathrm{Tr}$ ends Neurosci 2004;27:589-594.

41. Connor B, Young D, Yan Q, Faull RL, Synek B, Dragunow M. Brainderived neurotrophic factor is reduced in Alzheimer's disease. Brain Res Mol Brain Res 1997;49:71-81.

42. Ferrer I, Marin C, Rey MJ, Ribalta T, Goutan E, Blanco R, et al. BDNF and full-length and truncated TrkB expression in Alzheimer disease. Implications in therapeutic strategies. J Neuropathol Exp Neurol 1999; 58:729-739.

43. Lindvall O, Ernfors P, Bengzon J, Kokaia Z, Smith ML, Siesjö BK, et al. Differential regulation of mRNAs for nerve growth factor, brainderived neurotrophic factor, and neurotrophin 3 in the adult rat brain following cerebral ischemia and hypoglycemic coma. Proc Natl Acad Sci U S A 1992;89:648-652.

44. Kokaia Z, Nawa H, Uchino H, Elmér E, Kokaia M, Carnahan J, et al. Regional brain-derived neurotrophic factor mRNA and protein levels following transient forebrain ischemia in the rat. Brain Res Mol Brain Res 1996;38:139-144.

45. Miyake K, Yamamoto W, Tadokoro M, Takagi N, Sasakawa K, Nitta A, et al. Alterations in hippocampal GAP-43, BDNF, and L1 following sustained cerebral ischemia. Brain Res 2002;935:24-31.

46. Crutcher KA, Scott SA, Liang S, Everson WV, Weingartner J. Detection of NGF-like activity in human brain tissue: increased levels in Alzheimer's disease. J Neurosci 1993;13:2540-2550.

47. Lyketsos CG, Steele C, Baker L, Galik E, Kopunek S, Steinberg M, et al. Major and minor depression in Alzheimer's disease: prevalence and impact. J Neuropsychiatry Clin Neurosci 1997;9:556-561.

48. Green RC, Cupples LA, Kurz A, Auerbach S, Go R, Sadovnick D, et al. Depression as a risk factor for Alzheimer disease: The MIRAGE study. Arch Neurol 2003;60:753-759.

49. Gabryelewicz T, Styczynska M, Luczywek E, Barczak A, Pfeffer A, Androsiuk W, et al. The rate of conversion of mild cognitive impairment to dementia: predictive role of depression. Int J Geriatr Psychiatry 2007;22:563-567.

50. Rubin EH, Kinscherf DA, Grant EA, Storandt M. The influence of major depression on clinical and psychometric assessment of senile dementia of the Alzheimer type. Am J Psychiatry 1991;148:1164-1171.

51. Poon LW. Toward an understanding of cognitive functioning in geriatric depression. Int Psychogeriatr 1992;4 Suppl 2:241-266.

52. Forsell Y, Jorm AF, Winblad B. Association of age, sex, cognitive dysfunction, and disability with major depressive symptoms in an elderly sample. Am J Psychiatry 1994;151:1600-1604.

53. Zubenko GS, Moossy J, Kopp U. Neurochemical correlates of major depression in primary dementia. Arch Neurol 1990;47:209-214.

54. Lazarus LW, Newton N, Cohler B, Lesser J, Schweon C. Frequency and presentation of depressive symptoms in patients with primary degenerative dementia. Am J Psychiatry 1987;144:41-45.

55. Karege F, Perret G, Bondolfi G, Schwald M, Bertschy G, Aubry JM. Decreased serum brain-derived neurotrophic factor levels in major depressed patients. Psychiatry Res 2002;109:143-148. 